\title{
BMJ Open A cross-sectional analysis of pharmaceutical industry-funded events for health professionals in Australia
}

\author{
Alice Fabbri, ${ }^{1,2}$ Quinn Grundy, ${ }^{2}$ Barbara Mintzes, ${ }^{2}$ Swestika Swandari, ${ }^{2}$ \\ Ray Moynihan, ${ }^{3,4}$ Emily Walkom, ${ }^{5}$ Lisa A Bero ${ }^{2}$
}

To cite: Fabbri A, Grundy Q, Mintzes B, et al. A crosssectional analysis of pharmaceutical industry-funded events for health professionals in Australia. BMJ Open 2017;7:e016701. doi:10.1136/ bmjopen-2017-016701

- Prepublication history and additional material are available. To view these files please visit the journal online (http://dx.doi. org/10.1136/bmjopen-2017016701).

Received 3 March 2017 Revised 10 May 2017 Accepted 19 May 2017

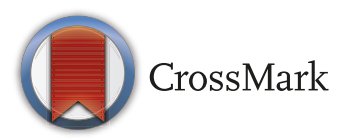

${ }^{1}$ Center of Research in Medical Pharmacology, The University of Insubria, Varese, Italy ${ }^{2}$ Charles Perkins Centre and Faculty of Pharmacy, The University of Sydney, Camperdown, Australia

${ }^{3}$ Faculty of Health Sciences and Medicine, Bond University, Robina, Australia

${ }^{4}$ Sydney Medical School - Public Health, The University of Sydney, Camperdown, Australia

${ }^{5}$ School of Medicine and Public Health, University of Newcastle, Newcastle, Australia

Correspondence to

Dr Lisa A Bero; lisa.bero@ sydney.edu.au

\section{ABSTRACT}

Objectives To analyse patterns and characteristics of pharmaceutical industry sponsorship of events for Australian health professionals and to understand the implications of recent changes in transparency provisions that no longer require reporting of payments for food and beverages.

Design Cross-sectional analysis.

Participants and setting 301 publicly available company transparency reports downloaded from the website of Medicines Australia, the pharmaceutical industry trade association, covering the period from October 2011 to September 2015.

Results Forty-two companies sponsored 116845 events for health professionals, on average 608 per week with 30 attendees per event. Events typically included a broad range of health professionals: $82.0 \%$ included medical doctors, including specialists and primary care doctors, and $38.3 \%$ trainees. Oncology, surgery and endocrinology were the most frequent clinical areas of focus. Most events $(64.2 \%)$ were held in a clinical setting. The median cost per event was \$A263 (IQR \$A153-1195) and over 90\% included food and beverages.

Conclusions 0 ver this 4-year period, industry-sponsored events were widespread and pharmaceutical companies maintained a high frequency of contact with health professionals. Most events were held in clinical settings, suggesting a pervasive commercial presence in everyday clinical practice. Food and beverages, known to be associated with changes to prescribing practice, were almost always provided. New Australian transparency provisions explicitly exclude meals from the reporting requirements; thus, a large proportion of potentially influential payments from pharmaceutical companies to health professionals will disappear from public view.

\section{INTRODUCTION}

Full disclosure of financial relationships between the pharmaceutical industry and health professionals is a key strategy adopted to make these interactions more transparent. Many jurisdictions have recently introduced transparency provisions, including the USA and the European Union, but the extent of the disclosure obligation varies. For example, meals and drinks fall outside the scope of disclosure obligations under new voluntary
Strengths and limitations of this study

- From publicly available reports released under Australian transparency rules, we have created a searchable world-first database with details of more than 100000 industry-sponsored events for health professionals, enabling researchers to analyse the intersection of pharmaceutical marketing and medical education.

- In order to analyse the database, we iteratively identified a set of keywords for each variable of interest; however, it is possible that some synonyms were missed.

- We relied on data as presented in the Medicines Australia transparency reports, and we did not verify the accuracy and completeness of data.

- Transparency requirements apply only to member companies, excluding manufacturers of generics, over-the-counter and non-member prescription medicine manufacturers; thus, our analysis likely underestimates the true extent of industry sponsorship of events for health professionals.

transparency provisions introduced by the European Federation of Pharmaceutical Industry Associations. ${ }^{1}$ At the same time, in the USA, over 100 medical societies recently backed a bill that would exempt pharmaceutical and medical device companies from reporting an entire category of payments to doctors: those related to continuing medical education. ${ }^{2}$

Australia was one of the first countries to move towards public reporting of these payments. Since 2007, Medicines Australia, the trade association of the prescription medicines industry, has required member companies to provide detailed reports of sponsorship of events for health professionals, which include company-initiated events, sponsored events organised by a third party, trade displays at educational events and sponsorship of healthcare professionals to attend events both in Australia and overseas. ${ }^{3}$ The reports are published on the Medicines 
Australia website and include events for all registered healthcare professionals, making Australia one of the few countries with transparency extending to non-physicians. ${ }^{45}$ These disclosure provisions were a condition for approval of Medicines Australia's Code of Conduct by the Australian Competition and Consumer Commission and were upheld following a legal appeal by industry. ${ }^{6} \mathrm{Changes}$ to this policy were introduced in 2015 , with the focus on events replaced by disclosure of payments to individuals. ${ }^{3}$ The reports detailing event sponsorship and aggregate payments to health professionals have been discontinued, and replaced with reports of payments to named individuals, similar to the Open Payments database in the USA. Moreover, the new code no longer requires reporting of payments for food and beverages.

At a time when disclosure policies are being debated and revised in several settings, ${ }^{1-3}$ Australian data can provide valuable insights into patterns of industry sponsorship and on characteristics of transparency provisions that are needed to capture expenditures of pharmaceutical companies on health professionals. Apart from two analyses of data from the first 6 months of the Australian disclosure scheme, ${ }^{47}$ and one brief report on events involving nurses, ${ }^{5}$ no comprehensive longer term analyses have been conducted.

The objectives of this cross-sectional analysis are to describe the nature and frequency of events for health professionals sponsored by pharmaceutical companies that are members of Medicines Australia; to create an open-access searchable database of these events; and to estimate the information that will be lost under newly introduced reporting standards.

\section{METHODS}

\section{Data sources}

We downloaded all the available reports from the Medicines Australia website (www.medicinesaustralia.com. $\mathrm{au}$ ) in PDF format. The 301 PDF reports of approximately 15000 pages covered the period October 2011 to September 2015. The PDFs had been originally created in Microsoft Excel. We requested the original Excel files from Medicines Australia but were refused on the basis that member companies had not given permission for their release. We converted the PDF files into Excel format using free, online converter programs, cleaned the data to address errors introduced during file conversion, and ensured consistency of reporting in each column.

The reports cover information on the sponsoring company, timing, venue type, number and profession of participants, hospitality and travel for attendees, room rentals and equipment, and speaker honoraria. ${ }^{3}$

Over this 4-year period, 47 pharmaceutical companies issued transparency reports, and we grouped them based on mergers and acquisitions as of 31 March 2016. Therefore our analysis included 42 Medicines Australia member companies; as a frame of reference, there are approximately 140 separate companies listed as suppliers to the Australian Pharmaceutical Benefit Scheme.

\section{Coding}

We designed a coding scheme based on the available data and variables of theoretical interest based on the literature on industry-professional interactions ${ }^{9}{ }^{10}$ and on two previous analyses of data from the first 6 months of the Australian disclosure scheme. ${ }^{4} 7$ The research team iteratively developed a set of keywords to define each variable of interest (see online supplementary file 1). Using Excel's filter function, we used the keywords to search the unstructured descriptive text and to dichotomously code event features as 'present/absent', for the following variables:

- sponsoring companies, grouped based on mergers and acquisitions as of 31 March 2016

- geographical location by Australian state or overseas location

- professional status of attendees (eg, specialists, nurses, trainees)

- clinical focus based on clinical specialty of attendees and event description (eg, oncology, endocrinology, cardiology)

- type of event (eg, journal club, workshop, in-services)

- type of hospitality provided (eg, breakfast, lunch, dinner).

\section{Statistical analysis}

We present frequency tables for the characteristics of the events, and median spending levels per event and company. Cost variables are reported in Australian dollars. As the data were not normally distributed, we used Mann-Whitney $\mathrm{U}$ tests for the differences between medians. Analyses were performed using SPSS V.22.

\section{RESULTS}

\section{General overview}

From October 2011 to September 2015, 42 pharmaceutical companies in Australia sponsored 116845 events involving health professionals. On average, there were 2434 events per month and 608 events per week. Each year, the number of events sharply decreased in December through February, likely reflecting the holiday season.

Table 1 provides illustrative examples of sponsored events as presented verbatim in the company reports, chosen to reflect variations in reporting and event type. Events varied greatly in scope and intensity, ranging from a half-hour journal club with sandwiches in a hospital meeting room, to a several-day conference with overseas flight, accommodation and hospitality provided. The professional status was sometimes described generically as 'healthcare professionals' or contained a list of the professions in attendees. The level of detail companies reported regarding the programme's content and the extent of explicit product promotion also varied; most of the event descriptions were disease-focused (eg, 'Journal 
Club on Chronic Obstructive Pulmonary Disease'), but in some cases the events mentioned specific drug names (eg, 'Introducing Zoely and other Emerging Trends in Contraception').

\section{Attendees}

Over this 4year period, there were 3481750 individual attendances at industry-sponsored events. The median number of event attendees was 18 (IQR 12-25); 97.2\% $(\mathrm{n}=113595)$ of the events had fewer than 100 attendees and $0.2 \%(\mathrm{n}=210)$ had more than 1000 participants. Over $40 \% \quad(n=47084)$ of events included participants from multiple professions. Table 2 lists the professional status of attendees and the most frequent clinical areas of focus for the events. Events were most frequently oncology-related, while otolaryngology and andrology were least represented.

\section{Location and characteristics of sponsored events}

Three-quarters of events were held in the three Australian states with the largest populations - New South Wales $(30.7 \%, \mathrm{n}=35888)$, Victoria $(26.9 \%, \mathrm{n}=31448)$ and Queensland (18.8\%, n=21963) — and few were held overseas $(1.9 \%, \mathrm{n}=2262)$. Nearly two-thirds of events $(64.2 \%$, $\mathrm{n}=74998$ ) were held in a clinical setting, such as hospitals, clinics or doctors' offices. Non-clinical venues included restaurants, hotels and convention centres. One-third of the events were described as a generic 'meeting' $(37.5 \%$, $\mathrm{n}=43810$ ), while others were described as journal clubs (28.5\%, $\mathrm{n}=33281)$, clinical meetings $(3 \%, \mathrm{n}=3533)$, grand rounds $(3.8 \%, \mathrm{n}=4472)$, in-services $(2.6 \%, \mathrm{n}=3038)$ or workshops $(2.6 \%, n=3029)$. Only $4.2 \%(n=4290)$ were described as scientific meetings (eg, conferences or congresses).

\section{Costs and hospitality}

Reporting companies spent \$A286117928 on events for health professionals. On average, companies spent \$A2449 per event (SD \$A15 020), while the median cost was \$A263 (IQR \$A153-1195). The median cost per person was $\$ A 14$ (IQR \$A10-68). In 81.7\% of the events $(\mathrm{n}=95483)$, the costs were below $\$ A 100$ per attendee, and in 2.1\% $(\mathrm{n}=2438)$ the costs were over $\$ A 1000$ per attendee.

Table 3 shows the median cost per person by characteristics of events. The median total cost per person was significantly higher when the event format was a scientific meeting such as a congress or conference (\$A93, IQR $\$$ A33-659) compared with other event types $(p<0.001)$, for events held overseas (\$A710, IQR \$A91-7300) compared with events held in Australia $(\mathrm{p}<0.001)$, or outside the clinical settings (\$A91, IQR \$A28-154) as compared with events in the clinical setting $(\mathrm{p}<0.001)$.

Reported 'hospitality or financial support' provided to attendees included registration fees, travel, accommodation, parking and food and beverage. Food was provided at $90.4 \%(\mathrm{n}=105667)$ of events: $22.2 \%$ included lunches $(\mathrm{n}=25935), 17.0 \%$ dinners $(\mathrm{n}=19873), 12.0 \%$ teas $\quad(n=14067), \quad 11.0 \%$ breakfasts $\quad(n=12806), 2.7 \%$ were all-day events with meals $(n=3113)$, and for $25.6 \%$ $(\mathrm{n}=29873)$ the type of food and beverage was unspecified. The total cost of food was more than $\$ A 84$ million (\$A84 862791 ), accounting for $29.7 \%$ of the total cost of these functions. However, for $65 \%(n=75949)$ of events, the total listed cost for food and beverage was equal to the listed total cost of the event, indicating that the company's sponsorship extended to food and beverage only. The median cost of food per person was $\$ A 12$ (IQR \$A8-20).

\section{The top companies}

Of the 42 pharmaceutical companies that provided reports, the top five in terms of the numbers of sponsored events were AstraZeneca, Novartis, Merck Sharp \& Dohme, Roche and Pfizer (table 4). Boehringer Ingelheim had the highest cost per event, with a median cost of \$A2007 (IQR \$A1308-2654), while Eli Lilly spent the least with a median cost per function of $\$ A 145$ (IQR \$A62-455). Table 4 provides an overview of event sponsorship by the top 20 companies, representing $87.8 \%$ of events.

\section{Availability of database}

The analysable data set in CSV file format we have created is available at (http:/ /dx.doi.org/10.4227/11/592631edbd9d5) (Direct link to the dataset: https://research-data. sydney.edu.au/index.php/s/npni79P4NhVQ0XB)

\section{DISCUSSION}

Pharmaceutical industry-funded events for health professionals were frequent and pervasive, with almost three and a half million individual attendances at over 116000 events in the 4-year period between 2011 and 2015. As a frame of reference, in 2014 there were 610148 registered health professionals in Australia, ${ }^{11}$ suggesting that there was wide exposure to these events. Events typically included a broad range of professionals and multidisciplinary teams, including most commonly medical specialists, nurses, trainees and primary care doctors. Nearly two-thirds of events were held in clinical settings. Average costs per person were modest, and the vast majority of events $(90.4 \%)$ included the provision of food and beverages. Additionally, for most events (65\%), the only funding provided was for food and beverages. Thus, our analysis suggests that the new Australian and European transparency rules will decrease transparency because hospitality in the form of food and/or beverages will be exempt from reporting. ${ }^{13}$

Although professional education is critical for improving patient care, previous studies of internal pharmaceutical industry documents have shown that sponsored events have been effectively used as a marketing tool. ${ }^{12}{ }^{13}$ A systematic review from 2010 found that with rare exceptions, exposure to pharmaceutical industry information is associated with either no effect on prescribing or with adverse effects such as lower prescribing quality, higher frequency or costs. ${ }^{14}$ 


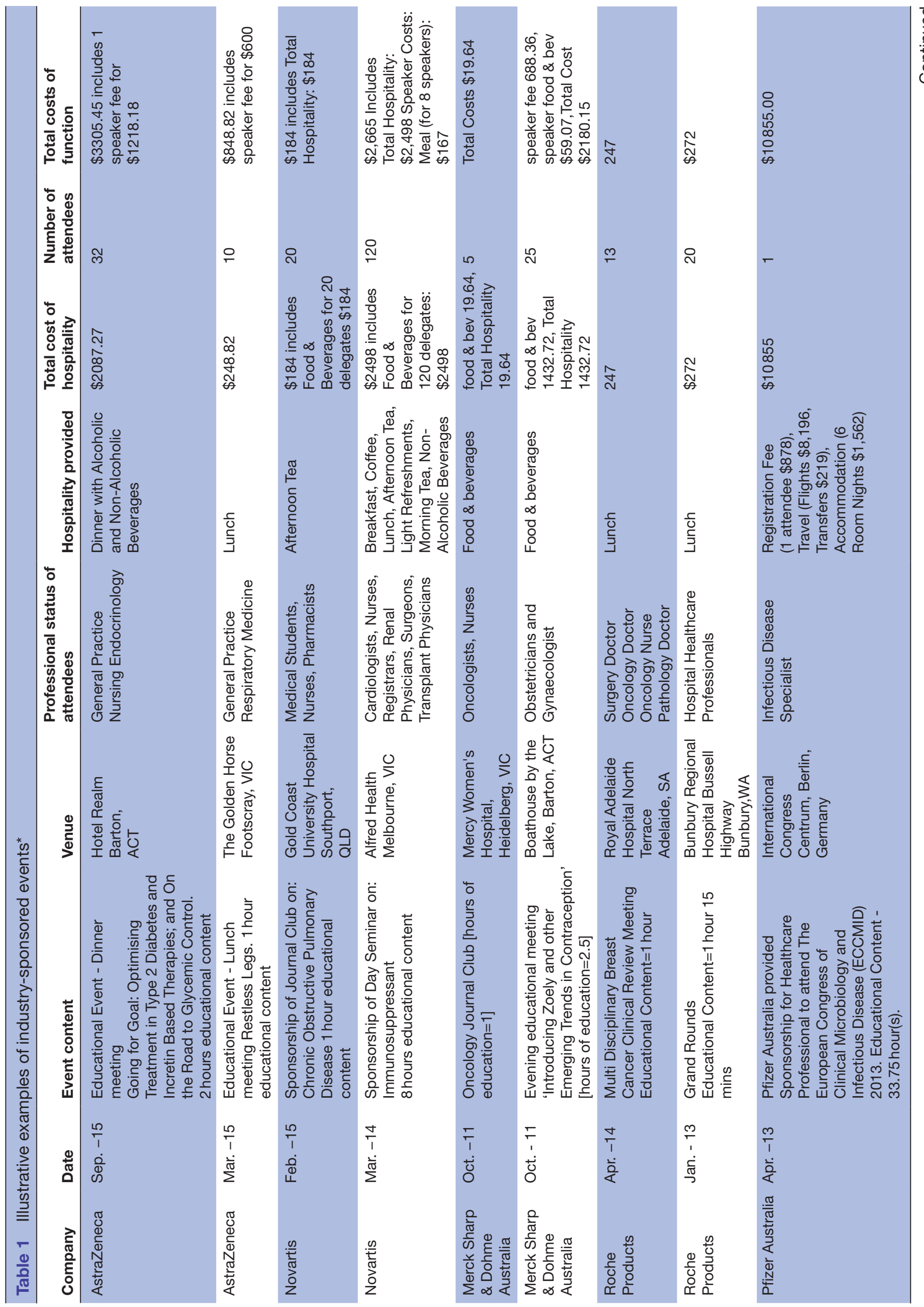

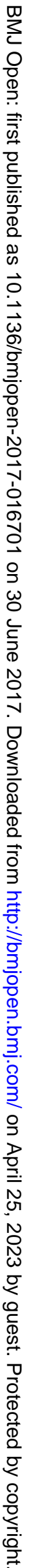


Table 2 Professional status of attendees and clinical areas of focus for the events $(n=116845)$

\begin{tabular}{|c|c|c|}
\hline Characteristics & Number of events & Per cent \\
\hline \multicolumn{3}{|c|}{ Professional status of attendees ${ }^{*}$} \\
\hline Medical specialists & 80060 & 68.5 \\
\hline Nurses & 46214 & 39.6 \\
\hline Trainees & 44774 & 38.3 \\
\hline Primary care doctors & 24662 & 21.1 \\
\hline Pharmacists & 9781 & 8.4 \\
\hline \multicolumn{3}{|l|}{ Clinical areas of focus } \\
\hline Oncology & 22987 & 19.7 \\
\hline Surgery & 13306 & 11.4 \\
\hline Endocrinology & 12655 & 10.8 \\
\hline Cardiology & 9033 & 7.7 \\
\hline Haematology & 8200 & 7.0 \\
\hline Respiratory medicine & 7659 & 6.6 \\
\hline Psychiatry & 6252 & 5.4 \\
\hline Nephrology & 6199 & 5.3 \\
\hline Gastroenterology & 5643 & 4.8 \\
\hline Pathology & 5361 & 4.6 \\
\hline Neurology & 4259 & 3.6 \\
\hline Urology & 4259 & 3.6 \\
\hline Radiology & 3667 & 3.1 \\
\hline Infectious diseases & 3348 & 2.9 \\
\hline Geriatrics & 3134 & 2.7 \\
\hline Anaesthesiology & 2746 & 2.4 \\
\hline Rheumatology & 2671 & 2.3 \\
\hline Paediatrics & 1994 & 1.7 \\
\hline Allergy/Immunology & 1398 & 1.2 \\
\hline Ophthalmology & 1365 & 1.2 \\
\hline Palliative care & 1319 & 1.1 \\
\hline Intensive care & 1147 & 1.0 \\
\hline Sexual health & 955 & 0.8 \\
\hline Dermatology & 913 & 0.8 \\
\hline Obstetrics/Gynaecology & 878 & 0.8 \\
\hline Emergency & 875 & 0.7 \\
\hline Internal medicine & 418 & 0.4 \\
\hline Neonatology & 363 & 0.3 \\
\hline Nuclear medicine & 357 & 0.3 \\
\hline Pharmacology & 219 & 0.2 \\
\hline Otolaryngology & 31 & 0.03 \\
\hline Andrology & 18 & 0.02 \\
\hline
\end{tabular}

*Percentages do not add to 100 because multiple types of professionals could attend an event.

More recently, analyses of the Open Payments database in the USA have shown that payments for educational training and even the provision of low-cost free meals, commonly provided at sponsored events, are associated 
Table 3 Characteristics of events and median cost per person

Number of events $n=116845, n(\%)$

Median total cost per person* (IQR)

\begin{tabular}{|c|c|c|}
\hline \multicolumn{3}{|l|}{ Location } \\
\hline Overseas & $2262(1.9 \%)$ & \$A710 (91-7300) \\
\hline Within Australia & $114583(98.1 \%)$ & \$A14 (10-62) \\
\hline \multicolumn{3}{|l|}{ Setting } \\
\hline Clinical setting & $74998(64.2 \%)$ & \$A12 (9-15) \\
\hline Non-clinical setting & 41847 (35.8\%) & \$A91 (28-154) \\
\hline \multicolumn{3}{|l|}{ Event type } \\
\hline $\begin{array}{l}\text { Scientific meeting (eg, congress, } \\
\text { conferences) }\end{array}$ & $4920(4.2 \%)$ & \$A93 (33-659) \\
\hline Other types of events & 111925 (95.8\%) & \$A14 (10-60) \\
\hline
\end{tabular}

*Includes hospitality as well as other costs (eg, venue hire, speaker honoraria, audiovisual hire).

with increased prescribing of promoted, costly, brandname medications. ${ }^{1516}$

Finally, we also found a high prevalence of trainee attendance at these events. Targeting medical trainees can lead to a process of normalisation and enculturation while trainees develop their professional identity. ${ }^{17}$ This has been described as an effective strategy 'to influence physicians from the bottom up'. ${ }^{13}$ Medical school policies limiting trainee-industry interaction have been associated with a shift in attitude ${ }^{18}$ and reduced prescribing of costly new medicines without therapeutic advantages. ${ }^{19}$

Our study has a number of limitations. First, we relied on reports submitted by companies to Medicines Australia and could not verify the accuracy and completeness of data. Second, since the Code of Conduct's transparency reporting requirements applies only to members of

Table 4 The top 20 companies in terms of number of sponsored events

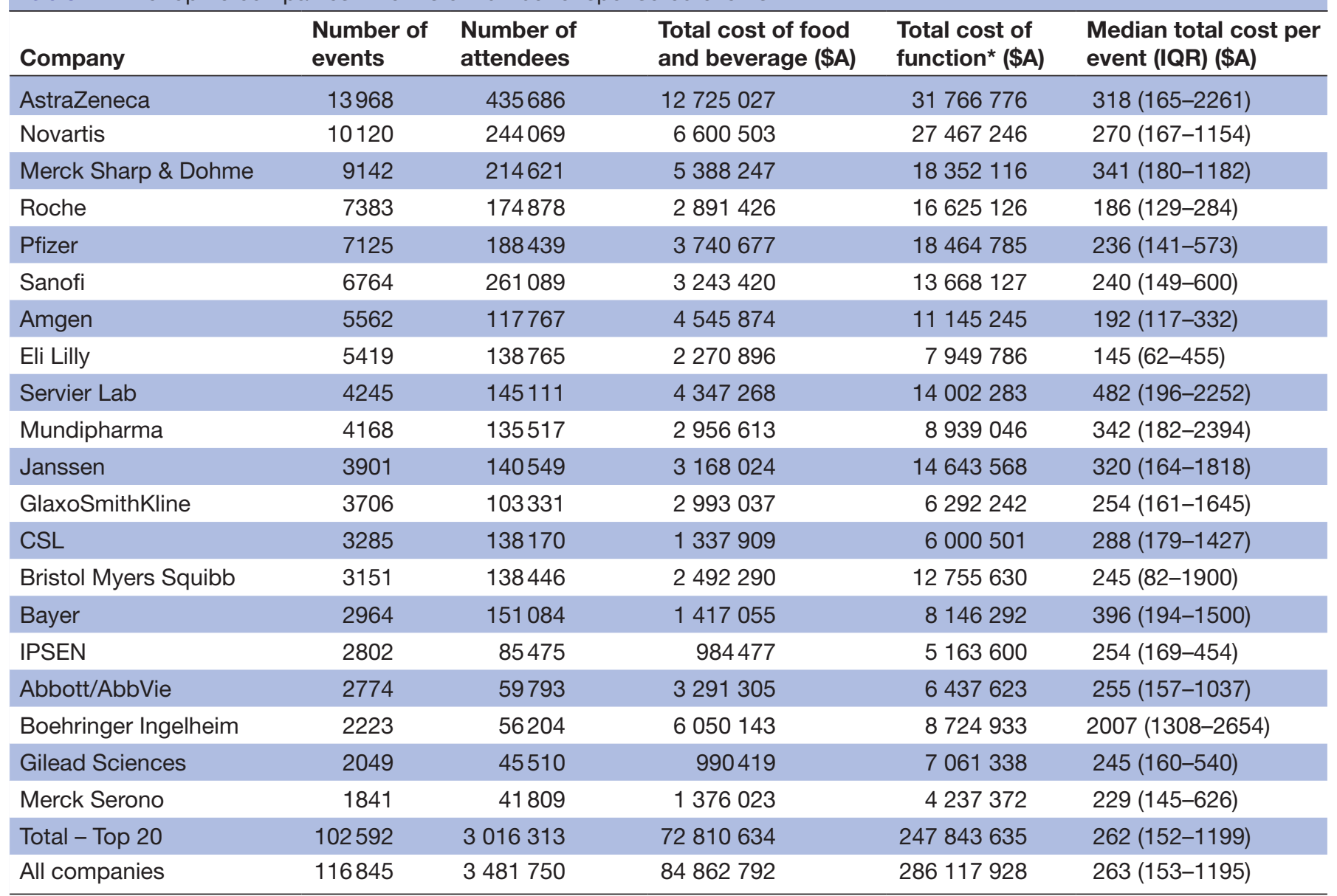

*Includes food and drink, as well as other costs (eg, venue hire, speaker honoraria, audiovisual hire). 
Medicines Australia, the available reports likely underestimate the true extent of industry sponsorship of events for health professionals. Our analysis included only 42 Medicines Australia member companies; as a frame of reference, approximately 140 manufacturers are listed as suppliers to the Australian Pharmaceutical Benefit Scheme. $^{8}$ Moreover, non-member manufacturers of branded prescription medicines, generic medicines, over-the-counter medicines and medical devices are not covered by the Medicines Australia Code. Third, with regard to the coding scheme, the research team identified a set of keywords to define each variable of interest, and it is possible that some synonyms were missed due to variability in the data provided. Fourth, we did not assess the content of events due to the unstructured and variable nature of reporting. Fifth, our analysis focuses on industry sponsorship of events and did not examine differences in how event organisers manage potential influences. Finally, costs were not adjusted for inflation as these would likely have a limited impact on the Australian dollar over such a short time period. Notwithstanding these limitations, we have conducted a cross-sectional analysis of the only publicly available data on industry-sponsored events for health professionals.

In conclusion, our findings have several international implications for future research and policy initiatives. While Australian transparency reports are difficult to analyse due to their format, we have created an open-access, searchable, world-first database with details of more than 100000 industry-sponsored events, enabling researchers to analyse the intersection of pharmaceutical marketing and medical education. Although the data included in this analysis are from Australia, pharmaceutical companies are transnational corporations whose practices are likely to be similar across different countries. Moreover, individual institutions such as hospitals or universities may use these data to see what industry-sponsored activities are happening within their own backyards, and whether they meet contemporary expectations for transparency and independence.

At the policy level, at a time when new rules are being debated and revised globally, our findings underscore the need for more disclosure, not less. Transparency rules should be as inclusive as possible with regard to the type of companies required to report and also in terms of the scope of payments and categories of health professionals covered. The onus of reporting should not be on the industry only; for example, public sector hospitals as well as universities and professional associations could report meal subsidies from pharmaceutical and device manufacturers. A stronger policy option, already implemented at several academic medical centres in the USA, would be to eliminate the provision of free food by manufacturers. ${ }^{20}$ In the long term, ways of expanding funding for independent continuing professional education should be explored. There are already case studies showing that independence from industry sponsorship is achievable. For example the University of Michigan, as well as other major medical institutions in the USA, no longer accepts commercial support for continuing medical education. ${ }^{21} 22$ This sets a valuable example that could become a model for other institutions. In the short term, universities and professional associations should make health professionals more aware of the independent sources of information on drugs that are already available (eg, NPS MedicineWise, the Australian Medicines Handbook and the independent drug bulletins).

Finally, our findings highlight that transparency requirements likely capture only a portion of industry sponsorship of events for health professionals. Changes to the transparency requirements will likely exacerbate this issue by excluding common categories of payments. Thus, decision-makers should be aware of the extent of industry-sponsored activity which will be hidden if 'free food' fails to be included in future transparency regimes.

Contributors AF, QG, BM, RM, LAB conceived of the study. AF, QG, BM, RM, EW designed the coding scheme. $A F, Q G$ and $S S$ acquired and analysed all data. $A F$ drafted the manuscript. All the authors contributed to the writing of the paper and approved the final version. AF is the guarantor.

Funding The work was partially funded via a University of Sydney Faculty of Pharmacy summer scholarship.

Competing interests All authors have completed the ICMJE uniform disclosure form at www.icmje.org/coi_disclosure.pdf (available on request from the corresponding author). BM reports that she was an expert witness on behalf of plaintiffs in a Canadian class action suit concerning cardiovascular risks of a testosterone gel. None of the authors received any payments, funding or other financial support from pharmaceutical manufacturers. The authors declare no other relationships or activities that could appear to have influenced the submitted work

Patient consent The study did not involve patients.

Provenance and peer review Not commissioned; externally peer reviewed.

Data sharing statement The analysable dataset in CSV file format is available at:http://dx.doi.org/10.4227/11/592631edbd9d5

Open Access This is an Open Access article distributed in accordance with the Creative Commons Attribution Non Commercial (CC BY-NC 4.0) license, which permits others to distribute, remix, adapt, build upon this work non-commercially, and license their derivative works on different terms, provided the original work is properly cited and the use is non-commercial. See: http://creativecommons.org/ licenses/by-nc/4.0/

(c) Article author(s) (or their employer(s) unless otherwise stated in the text of the article) 2017. All rights reserved. No commercial use is permitted unless otherwise expressly granted.

\section{REFERENCES}

1. EFPIA Code on disclosure of transfers of value from pharmaceutical companies to healthcare professionals and healthcare organisations. 2014 http://transparency.efpia.eu/uploads/Modules/Documents/ efpia-disclosure-code-2014.pdf accessed on 5 September 2016.

2. Rubenfire A. Doctors back bill to exempt CME from Open payments reporting. Modern Healthcare 2016;22 http://www.modernhealthcare. com/article/20160722/NEWS/160729951.

3 . Medicines Australia, Code of Conduct Edition 18, 2015. https:// medicinesaustralia.com.au/wp-content/uploads/sites/52/2010/01/ 20150617-PUB-Code-Edition-18-FINAL.pdf (accessed 20 Sep 2016).

4. Robertson J, Walkom E, Moynihan R, et al. Pharmaceutical industry funding of educational events for pharmacists in Australia: an analysis of data from the first 6 months of a mandatory disclosure programme. Int J Pharm Pract 2010;18:88-92.

5. Grundy Q, Fabbri A, Mintzes B, et al. The Inclusion of Nurses in Pharmaceutical Industry-Sponsored events: guess who is also coming to Dinner? JAMA Intern Med 2016;176:1718-20.

6. Australian Competition and Consumer Commission. Australian competition tribunal affirms ACCC's decision on extra reporting for 
Medicines Australia Code. Press release 2007;27 http://www.accc. gov.au/content/index.phtml/itemld/790845/fromltemld/621589? pageDefinitionltemld $=16940$.

7. Robertson J, Moynihan R, Walkom E, et al. Mandatory disclosure of pharmaceutical industry funded events for health professionals. PLOS Med 2009;6:e1000128.

8. Department of industry, Innovation and Science of the Australian Government. Pharmaceuticals Industry Profile. https://industry.gov. au/industry/IndustrySectors/PharmaceuticalsandHealthTechnologies/ Pharmaceuticals/Pages/PharmaceuticalsIndustryProfile.aspx accessed 3 Apr 2017.

9. Henry DA, Kerridge IH, Hill SR, et al. Medical specialists and pharmaceutical industry-sponsored research: a survey of the australian experience. Med J Aust 2005;182:557-60.

10. Wazana A. Physicians and the pharmaceutical industry: is a gift ever just a gift? JAMA 2000;283:373-80.

11 . Australian Institute of Health and Welfare. http://www.aihw.gov.au/ workforce/ (accessed on 16 November 2016).

12. Moynihan R. Doctors' education: the invisible influence of drug company sponsorship. BMJ 2008;336:416-7.

13. Steinman MA, Bero LA, Chren MM, et al. Narrative review: the promotion of gabapentin: an analysis of internal industry documents. Ann Intern Med 2006;145:284-93.

14. Spurling GK, Mansfield PR, Montgomery BD, et al. Information from pharmaceutical companies and the quality, quantity, and cost of physicians' prescribing: a systematic review. PLOS Med 2010;7:e1000352.
15. Yeh JS, Franklin JM, Avorn J, et al. Association of Industry Payments to Physicians With the Prescribing of Brand-name Statins in Massachusetts. JAMA Intern Med 2016;176:763-8.

16. DeJong C, Aguilar T, Tseng CW, et al. Pharmaceutical IndustrySponsored Meals and Physician Prescribing Patterns for Medicare Beneficiaries. JAMA Intern Med 2016;176:1114-10.

17. Austad KE, Avorn J, Kesselheim AS. Medical students' exposure to and attitudes about the pharmaceutical industry: a systematic review. PLoS Med 2011;8:e1001037.

18. Kao AC, Braddock C, Clay M, et al. Effect of educational interventions and medical school policies on medical students' attitudes toward pharmaceutical marketing practices: a multiinstitutional study. Acad Med 2011;86:1454-62.

19. King M, Essick C, Bearman P, et al. Medical school gift restriction policies and physician prescribing of newly marketed psychotropic medications: difference-in-differences analysis. BMJ 2013;346:f264.

20. American Medical Student Association. Conflict of interest policies at Academic Medical Centers. Scorecard 2014 http://amsascorecard. org/ accessed 4 Nov 2016.

21. Hutchinson RJ, Woolliscroft JO, Roll LC. U-M Medical School plans changes to Continuing Medical Education funding. . Available at http://www.uofmhealth.org/u-m-medical-school-plans-changescontinuing-medical-education-funding accessed 6 Apr 2017.

22. Smith SR, Hams M, Wilkinson W. Policy Guide for Academic Medical Centers and Medical Schools. Toolkit on Continuing Medical Education. Available at http://www.communitycatalyst.org/doc-store/ publications/CME_toolkit.pdf accessed 6 Apr 2017. 